\title{
Analysis of the components of social reinforcement of infant vocalization*
}

\author{
ANDREW SCHWARTZ, University of Denver, Denver Colo. 80202 \\ DANA ROSENBERG, Southeastern Louisiana College, Hammond, La. 70401 \\ and
}

YVONNE BRACKBILL, Georgetown University Medical School, Washington D.C. 20007

The results of two studies indicated that infant vocalizations can be conditioned by using only one or two elements of the traditionally employed composite social reinforcer, consisting of auditory, tactile, and visual stimuli. It was also found that the components, both singly and in pairs, are of relatively equal effectiveness in increasing response rate.

Social responses of infants, particularly smiling and vocalization, have received increasing attention by developmental psychologists during the past few years. However, very few investigators have attempted to condition these responses using operant techniques. Brackbill (1958) has demonstrated that smiling in 4-month-old infants will increase when followed by an adult's social response. Infants' vocal behavior has also been shown to respond to conditioning (Rheingold, Gewirtz, \& Ross, 1959; Routh, 1969; Weisberg, 1963).

In each of these studies the social reinforcer used was a composite one, a complex of stimuli consisting of auditory (A), visual (V), and tactile (T) components simultaneously administered by E. (This complex will be referred to as AVT.) The problem still remains as to the relative effectiveness of these components considered separately or in pairs. Todd \& Palmer (1968), for example, have suggested that the human voice alone may be an effective reinforcer in increasing infants' rate of vocalization. Brossard and Décarie (1968) have suggested that picking the infant up is the most effective way of increasing his rate of smiling.

Two studies are presented here. The initial study attempted to analyze the effectiveness for conditioning infant vocalizations of different dual-component reinforcement combinations (AV, AT, TV). A second study examined the reinforcing effectiveness of single components. Thus, the questions under investigation were (1) whether or not infant vocalizations can be conditioned, using only a part or parts of the composite social reinforcer traditionally employed,

*This paper is based in part on Master's theses submitted to the University of Denver by the first and second authors. The research was supported in part by USPHS Training Grant MH 8297, by USPHS Research Career Grant MH 5925, and by NSF Research Grant GB 4784. The authors wish to thank Catholic Charities for its help in referring Ss. and (2) whether or not any component is relatively more effective than another. It was necessary to complete the first study before beginning the second, because the investigators could gain no earlier assurance that enough infant Ss from the referring institutions would be available to complete both studies.

\section{SUBJECTS}

In Experiment 1, 16 normal, full-term infants served as Ss. Their ages at the beginning of experimentation ranged from 70 to 117 days, with a mean of 90 days; 7 infants were male and 9, female. Fifteen of the infants resided in a nursery in New York City; the other infant resided in a nursery in Denver, Colorado.

In Experiment 2 the Ss were 12 normal, full-term infants. Their ages ranged from 70 to 120 days, with a mean of 83 days; 7 Ss were male and 5, female. Six of the infants were obtained from the New York City residential nursery and the other six from the Denver nursery.

Three infants were not accepted as Ss because of unconditionably high baseline vocalization rates. Another three infants were lost during the course of experimentation through adoption or illness.

In both studies Ss were assigned to groups such that baseline vocalization rates between groups were roughly equated. This restriction did not result in any significant age or sex differences among groups.

DE SIGN AND PROCE DURE Experiment 1

This study investigated the effectiveness for conditioning of different combinations of reinforcing components. There were four groups of four Ss each. The groups differed in terms of the type and number of reinforcing events administered. These reinforcing events were as follows. Auditory reinforcement consisted of a $1-\mathrm{sec}$ tape-recorded female voice saying "nice baby." Visual reinforcement consisted in E's smiling and nodding his head. Tactile reinforcement was provided by E's rubbing S's abdomen with the palm of his hand. During the administration of auditory and tactile reinforcement, E's face remained expressionless and motionless in S's visual field. The separate reinforcement components were combined in the following fashion: Group AV received auditory and visual reinforcement; Group AT received auditory and tactile reinforcement; Group TV received tactile and visual reinforcement; and Group AVT received auditory, visual, and tactile reinforcement. This last procedure is essentially the same as that used by Rheingold et al (1959).

There were two Es, one male and one female. Each administered social reinforcement to half the Ss in each group. In order to reduce differences in appearance between Es, both wore a white surgical gown and a blond wig. Any remaining $\mathrm{E}$ differences were not reflected in the results.

Experimental sessions were limited in length to $20 \mathrm{~min}$ each and in number to two a day. At the beginning of any session, the infant had just been fed, freshly diapered, and was in a quiet awake state.

The experimental procedure itself was divided into three periods: baseline, conditioning, and extinction. During the baseline period, which lasted for two 20-min sessions, the unconditioned rate of vocalizing was measured. For this purpose, E leaned over the side of the crib, approximately $20 \mathrm{in}$. above S's face, and impassively observed the infant. A second $E$, out of S's sight, tallied the number of vocalizations in 30-sec intervals. In line with the definition used by Rheingold et al (1959), a vocalization was defined as a "discrete voiced sound produced by $S$ " appearing within one breath. Protests such as fussing and crying were not counted, nor were coughs and sneezes. In terms of absolute number of agreements between two trained judges, out of $140 \quad 10-\mathrm{sec}$ observations, 125 , or $90 \%$, agreed perfectly, 13 , or $9 \%$, disagreed by one response per observation unit, and 2 , or $1 \%$, disagreed by two responses.

During the conditioning period $\mathrm{E}$ immediately reinforced each response that occurred. The components of reinforcement were administered simultaneously and lasted for approximately $2 \mathrm{sec}$. This procedure continued either until $S$ had achieved a vocalization rate at least 2.5 times that of his baseline rate and had sustained it for 5 consecutive minutes or until three consecutive 20 -min sessions (60 min) had passed without the infant's reaching this criterion. Each S's score was the number of minutes taken to reach criterion.

. When criterion was achieved, extinction began in the next session. The procedure 
Table 1

Vocalization Rate During Baseline and Second Extinction Period and Time to Criterion During Conditioning

\begin{tabular}{|c|c|c|c|c|}
\hline \multicolumn{2}{|c|}{$\begin{array}{l}\text { Experimental } \\
\text { Group }\end{array}$} & $\begin{array}{c}\text { Baseline: } \\
\text { Mcan number of } \\
\text { vocalizations } \\
\text { per minute }\end{array}$ & $\begin{array}{l}\text { Conditioning: } \\
\text { Mean number of } \\
\text { minutes to } \\
\text { criterion }\end{array}$ & $\begin{array}{l}\text { Extinction: } \\
\text { Mean number of } \\
\text { vocalizations } \\
\text { per minute }\end{array}$ \\
\hline 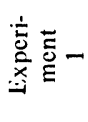 & $\begin{array}{l}\text { AVT } \\
\text { AV } \\
\text { AT } \\
\text { TV }\end{array}$ & $\begin{array}{l}1.33 \\
1.08 \\
1.14 \\
1.45\end{array}$ & $\begin{array}{l}17.13 \\
20.50 \\
17.50 \\
18.89\end{array}$ & $\begin{array}{r}.94 \\
1.28 \\
.84 \\
1.19\end{array}$ \\
\hline 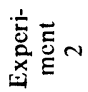 & $\begin{array}{l}\mathrm{A} \\
\mathrm{V} \\
\mathrm{T}\end{array}$ & $\begin{array}{l}.97 \\
.99 \\
.99\end{array}$ & $\begin{array}{l}20.50 \\
14.10 \\
16.83\end{array}$ & $\begin{array}{l}.24 \\
.59 \\
.45\end{array}$ \\
\hline
\end{tabular}

used during this period was identical to that used during baseline: E leaned over the side of the crib with an expressionless face and made no response to S's vocalizations. This continued for two 20-min sessions.

Experiment 2

This study investigated the effectiveness of single-component social reinforcers for conditioning vocalizations. The design and procedure used were the same as for Experiment 1 except that during the conditioning phase, Ss' vocal responses were now followed either by auditory stimulation alone (Group A), visual stimulation alone (Group V), or tactile stimulation alone (Group T). The conditioning criterion and method of scoring were the same as had been used in Experiment 1.

\section{RESULTS}

The questions under investigation were (1) whether infant vocalizations can be conditioned using only a component or components of the traditionally employed complex reinforcer, and (2) whether such reinforcement is as effective as the complex reinforcer.

Mean number of vocalizations for all experimental groups during baseline are given in Table 1. The baseline data for Experiment 1 were subjected to an analysis of variance for repeated measures; this revealed no significant differences in vocalization rates either between groups or across 20 -min sessions during the baseline period. Thus, all four groups were effectively equated for baseline levels, and there was no systematic change in vocalization rate due to time. A parallel analysis of the baseline data from Experiment 2 yielded similar results.

Table 1 also shows, for the conditioning phase, the mean time in minutes up to and including criterion for the groups of both experiments. The criterion of conditioning, it will be recalled, was achievement of a vocalization rate at least 2.5 times that of the individual S's baseline rate and, subsequently, maintenance of this rate for 5 consecutive minutes. (All seven groups evidenced conditioning, although one infant in Experiment 2 failed to reach criterion under tactile stimulation alone after a total of $60 \mathrm{~min}$ of conditioning.) The mean difference in vocalization rate from baseline to criterion interval was significant in both experiments: for Experiment $1, \mathrm{t}=4.32, \mathrm{df}=15, \mathrm{p}<.001$. and for the single-component reinforcers of Experiment 2, $\mathrm{t}=4.70, \mathrm{df}=10, \mathrm{p}<.001$. Mean differences in vocalization rate between the 5 -min criterion interval and the last $5 \mathrm{~min}$ of the extinction period showed similar results. For these comparisons the data from the last $5 \mathrm{~min}$ of the extinction period were used because unlike the results obtained during baseline, mean vocalization rate during extinction decreased over trials; for Experiment 1 the mean difference in vocalization rate between first and second extinction sessions was significant $(t=2.39, d f=15$, $\mathrm{p}<.05)$, and for Experiment 2 it approached significance $(\mathrm{t}=1.89, \mathrm{df}=10$, $\mathrm{p}=.10)$. There were significant decreases in mean vocalization rate from the $5-\mathrm{min}$ criterion interval to the last $5 \mathrm{~min}$ of extinction for both experiments: for Experiment 1, $\mathrm{t}=5.32, \mathrm{df}=15, \mathrm{p}<.001$, and for Experiment 2, $\mathrm{t}=2.21, \mathrm{df}=10$, $p=.05$.

Both the increase in vocalization rate from baseline to conditioning and the decrease from conditioning to extinction suggest a positive answer to the first question asked in this study by indicating that a social response such as infant vocalizations can be conditioned when the reinforcement used consists of only one or two components of the more traditionally employed multiplicity of reinforcing events.

Two approaches were employed in investigating the second question, whether or not there is any differential effectiveness among such reinforcing components. Analyses of variance compared time-to-criterion scores for the three two-component groups of Experiment 1 as well as for the three single-component groups of Experiment 2. The : sulting values of $F$ were less than 1 in both cases. In the second approach, a planned comparison itas lised to compare time-to-criterion scores for the three-component group vs the two-component groups and for the two-component groups vs the single-component gloups. In this case again. the results were not significant; in both instances $1<1.00$. By either method of analysis, then, it appears that no one of the reinforcing events represented in these experiments is more effective than another This finding does not accord with the suggestion that either the human voice (Todd \& Palmer, 1968) or kinestheticvestibular stimulation (Brossard \& Décarie, 1968) is a particularly effective type of reinforcement for early social responses. Interestingly enough, evidence for response-reinforcement interaction specificity in the classical conditioning of infants has been found (Brackbill, Lint\%, \& Fitzgerald, 1968; Abrahamson, Brackbill, Carpenter, \& Fitzgerald, in press). The present results suggest that such specificity is much less apparent for operant conditioning, if indeed it exists at all.

Another inference may be drawn from the finding that one reinforcing event is as effective as two and that two reinforcing events are as effective as three. This has to do with the argument, sometimes raised by ethologists, that what learning psychologists regard as a reinforcer of social responses may in fact be a social releaser of such behavior. In the present situation, if the reinforcing stimuli acted as releasers or elicitors of vocalizations, then the greater their number or intensity, the more vigorous and frequent should have been the resulting vocalizations. That this was not the case, however. was indicated by the fact that vocal responding does not increase as a function of stimulus events. ${ }^{1}$ Hence, there is no compelling reason for calling these events "social releasers." On the other hand, the fact that the behavior in question, vocalization, did respond to an operant conditioning procedure in the way that other, nonsocial operants respond. suggests that basic principles of conditioning provide a more appropriate, heuristic framework within which to view the developmental progressions of social behavior.

\section{REIFERENCES}

ABRAHAMSON, D., BRACKBILL, Y., CARPENTIR, R., \& IITZGERALD, H. F. Interaction of stimulus and response in infant conditioning. Psychosomatic Medicine, 1970 , 32, 319-325.

BRACKBILL, Y. Ixtinction of the smiling response in infants as a function of reinforcement schedule. Child Development, 1958, 29, 115-124.

BRACKBILL, Y., LINT7, L. M.. \& IITZGFEALD, H. E. Differences in the autonomic and somatic conditioning of infants. Psychosomatic Medicunc. 1968. 30. 193-201 
BROSSARD, L. M., \& DECARIE, T. G. Comparative reinforcing effect of eight stimulations on the smiling response of infants. Journal of Child Psychology \& Psychiatry, 1968, 9, 51-59.

RHEINGOLD, H. L., GEWIRTZ, J. L., \& ROSS, $H$. W. Social conditioning of vocalizations in the infant. Journal of Comparative \& Physiological Psychology, 1959, 52, 68-73.

ROUTH, D. K. Conditioning of vocal response differentiation in infants. Developmental
Psychology, 1969, 1, 219-226.

TODD, G. A., \& PALMER, B. Social reinforcement of infant babbling. (hild Development, 1968, 39, 591-597.

WIISBI:RG, P. Social and nonsocial conditioning of infant vocalizations. Child Development, $1963,34,377-388$

\section{NOTE}

1. Nor does it increase through the use of noncontingent reinforcement (Weisberg, 1963).

\section{The effect of expected difficulty on psychophysical judgment*}

\author{
E. SCOTT GELLER \\ Virginia Polytechnic Institute, Blacksburg, Va. 24061
}

The effect on psychophysical judgments of pretask instructions that indicated the degree of task difficulty was studied. Prior to estimating the midpoints of various line lengths, one experimental group was told that the judgment task was difficult and to expect large errors, while another group was instructed that the task was easy and to expect few judgment errors. The average deviations of midpoint judgments from the measured midpoint of various line lengths was reliably larger for the group instructed to expect large deviations.

The social psychologist, who often deals with phenomena about which Ss hold preconceived notions and who manipulates various situational cues in an attempt to deceive Ss about the true purpose of his experiment, has recently become sensitized to the extraneous influence of Ss' expectations. For example, as independent variables, S's suspiciousness of E's intent (McGuire, 1969) and the demand characteristics of the experimental situation (Orne, 1969) have aroused considerable theoretical, as well as methodological, interest. The expectation produced by experimental instructions has been shown to influence Ss' performance on various tasks in an experiment involving beliefs about sensory deprivation (Orne \& Scheibe, 1964) and to bias perceptual motor skills in a business setting (Jastrow, 1900).

Unlike earlier investigations, the present study investigated the effect of pretask instructions in a psychophysical experiment involving few explicit social cues and little interpersonal interaction between $\mathrm{S}$ and $\mathrm{E}$. Ss were required to estimate the midpoint of printed lines of various lengths, to measure the lines and

*The study was performed at Southern Illinois University. determine the actual midpoint, and to calculate the difference between these two values. One experimental group (Group HARD) was instructed that the task was difficult and to expect large errors; another group (Group EASY) was told that the task was easy and to expect few errors.

\section{METHOD}

Two experimental psychology laboratory sections, each composed of 17 undergraduate juniors and seniors of Southern Illinois University, served as the experimental groups. Group HARD comprised 15 males and 2 females; Group EASY consisted of 13 males and 4 females.

The $\mathrm{E}$ distributed to each $\mathrm{S}$ a sharp pencil, a millimeter scale, and 10 sheets of paper upon which were printed lines of varying lengths. Each page contained a $25-$, 50-, 75-, 100-, 125-, and 150-mm line. The lines were printed in irregular positions and arranged in a different random order on each page. E instructed each group to estimate the midpoint of each line, then measure each line to find the true midpoint, and record the difference between the estimated and true midpoints for every line. After answering all questions, E made a distinct statement to each experimental group indicating the degree of difficulty of the task and what

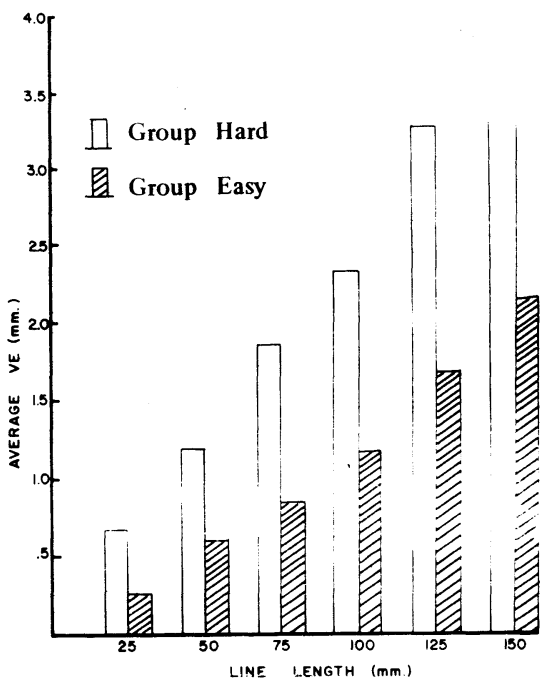

Fig. 1. Average variable error as a function of line length for Group HARD and Group EASY.

results to expect. Specifically, Group HARD was told to expect large differences between the estimated and the measured midpoint, since students typically have found the task to be quite difficult. Group EASY was told that other students had found the psychophysical judgment task to be easy and therefore to anticipate quite accurate midpoint estimations.

Within $1 \mathrm{~h}$ all Ss had obtained observed and measured midpoints of all the line lengths and had calculated the deviations. The average variable error for each particular line length was determined by dividing the absolute sum of the deviations for all trials of a particular line length by the number of trials.

\section{RESULTS AND DISCUSSION}

Figure 1 depicts, for each instruction condition, the average VE for each line length. For both conditions, the mean VE varied directly with the length of the stimulus line. Group HARD, expecting large errors, had a reliably larger VE for each line length than did the group told to expect few errors (Group EASY). A t test at every line length indicated that the group differences were significant beyond the .02 level.

Consequently, the results of the present study indicated that psychophysical judgments were sensitive to variation in pretask instructions. Similarly, Jastrow (1900) reports that perceptual-motor coordination may become impaired due to an expectancy that the ensuing task will be difficult and that failure is probable. He gives a detailed account of the effects of task-difficulty anticipations on card-punching performance for the United 